\title{
Prevalence of extended spectrum beta lactamase producing Escherichia coli and Klebsiella pneumoniae urinary isolates in a tertiary care hospital in Kathmandu, Nepal
}

\author{
Anil Chander ${ }^{*}$ and Chandrika Devi Shrestha
}

\begin{abstract}
Background: Escherichia coli and Klebsiella pneumoniae are the major bacterial pathogens being isolated and reported from mid stream urine (MSU) specimens, globally. These uropathogens are mostly implicated as the major extended spectrum beta-lactamase (ESBL) producers, severely limiting the therapeutic management in cases of urinary tract infections. Limited studies had been reported from Nepal investigating the ESBL producers among uropathogens. This study was designed to assess the prevalence of ESBL producing E.coli and K. pneumoniae in urinary isolates at a centrally located major tertiary care hospital in Kathmandu valley, Nepal.

Methods: Between September 2011 and May 2012, during the nine months period, 6308 MSU specimens were collected aseptically from the same number of clinically suspected patients of urinary tract infections. The samples were cultured on MacConkey agar and blood agar. The isolates with significant bacteriuria ( $10^{5} \mathrm{CFU} / \mathrm{ml}$ ) were identified based on standard laboratory procedures. Antimicrobial susceptibility tests were carried out using various antimicrobial discs alongwith ceftriaxone on E.coli and K. pneumoniae isolates by Kirby Bauer disc diffusion method as per the recommendations of CLSI. On initial screening with ceftriaxone $(30 \mu \mathrm{g})$ disc showing resistance was then confirmed for ESBL production by phenotypic confirmatory disc diffusion test (PCDDT) using ceftazidime (30 ug) and ceftazidime + clavulanic acid (30 $\mu \mathrm{g}+10 \mathrm{ug})$ disc as per guidelines of CLSI (2011).
\end{abstract}

Results: Out of a total of 6308 MSU specimens investigated for significant bacteriuria, E.coli isolates were 444 (7.04\%) and K.pneuminiae were 145 (2.3\%) making a total of 589 (9.34\%). Initial screening with ceftriaxone disc revealed 155 isolates of E.coli and 70 isolates of K.pneumoniae to be resistant. Further testing by PCDDT method showed $60 / 444(=13.51 \%)$ of $E$. coli and $24 / 145(=16.55 \%)$ of $K$. pneumoniae isolates to be confirmed ESBL producers. These ESBL - producer uropathogens showed high degree of resistance to ceftriaxone (100.0\%), amoxycillin, fluoroquinolones and co-trimoxazole.

Conclusion: An emerging and moderately high prevalence of ESBL-producing E. coli and K. pneumoniae was observed and confirmed in the urinary isolates investigated. It is essential to have a regular and routine monitoring of ESBL producing clinical isolates in laboratory practice.

Keywords: Antimicrobial resistance, Extended spectrum beta lactamase (ESBL), Escherichia coli, Klebsiella pneumoniae, Mid stream urine (MSU), Prevalence, Urinary isolates

\footnotetext{
* Correspondence: dranilchander@yahoo.co.in

Department of Microbiology, Kathmandu Medical College Teaching Hospital Sinamangal / Duwakot, Kathmandu, Nepal
}

\section{Biomed Central




\section{Background}

Antimicrobial resistance among bacterial strains is an emerging problem, worldwide. Urinary tract infections (UTIs) are one of the most common bacterial infections in humans both in the community and the hospital settings [1-3]. Escherichia coli and Klebsiella pneumoniae are the two pre-dominant pathogens commonly isolated in urine. These uropathogens have also developed resistance to commonly prescribed antimicrobial agents, This severely limits the treatment options of an effective therapy.

Primarily, these uropathogens exerts their antimicrobial resistance against beta-lactams by producing extended spectrum beta-lactamases (ESBLs) enzymes that confers bacterial resistance to all beta-lactams except carbapenems, cephamycins and clavulanic acid [4-6]. ESBLs are class A beta-lactamases, and are plasmid-mediated enzymes that hydrolyze oxyimino-cephalosporins and monobactams, with various genotypes such as SHV, TEM, CTX-M, VEB, PER, BEL-1, BES-1, TLA and IBC $[7,8]$. Further, plasmids carrying ESBLs are transferable from one bacterial strain to the next and between different bacterial species [8]. ESBLs are clinically significant and when detected, indicate the need for the use of appropriate antibacterial agents. The mortality rate in misdiagnosed patients with ESBLs producing UTIs have ranged from 42-100\% [9-11]. Antibacterial choice is often complicated by multi-resistance. There is an increasing association between ESBL production and fluoroquinolone resistance [12,13] and aminoglycoside resistance [14]. Multi-drug resistance (MDR) among ESBL expressing strains is complex and is influenced by the location of resistance genes on integrons that possess promoters that drive the co-ordinated expression of downstream resistance cassettes [15]. Thus, multi-resistance has severely limited the treatment options for ESBLs producing strains of Enterobacteriaceae. More recently, the emergence of carbapenem resistance has been reported among ESBL producing organisms [8].

The prevalence of bacteria producing ESBLs varies world-wide, with reports from North America, Europe, South America, Africa and Asia [16-18]. There is ample evidence to suggest the spread of ESBL infections is higher in resource poor countries $[19,20]$.

Limited number of studies had been reported in this regard from Nepal [21-23]. This study was thus designed to estimate the current prevalence and antimicrobial resistance patterns among ESBL producing urinary isolates of E.coli and K.pneumoniae in a centrally located tertiary care centre in Kathmandu valley, Nepal.

\section{Methods}

\section{Setting}

This investigation was carried out in the Department of Microbiology, Kathmandu Medical College Teaching
Hospital (affiliate Kathmandu University), a tertiary healthcare facility centrally located in the capital city of Kathmandu, Nepal. Ethical approval was not required to carry out this work as the bacterial isolates were collected as part of standard patient care investigation.

\section{Specimens}

Between 1st September 2011 and 31st May 2012, 6308 consecutive and non-duplicate mid-stream urine specimens were collected aseptically from clinically suspected patients of UTIs attending outpatient and inpatient departments (medicine, surgery, paediatrics and gynecology and obstetrics) of the hospital. Urine specimens were transported to the Department of Microbiology laboratory and processed immediately.

\section{Inclusion criteria}

Patients who did not have a course of antibiotics at least two weeks prior to selection in the study.

\section{Identification of isolates}

The urine sample was cultured on to MacConkey agar and blood agar plates and incubated at $37^{\circ} \mathrm{C}$ for 24 hours and the colonies identified based on morphology and gram negative bacilli isolated were characterized by performing gram's staining, motility and standard biochemical tests [24].

\section{Anti-microbial susceptibility testing}

E.coli and K. pneumoniae isolates were selected to determine their susceptibility patterns against the first line antimicrobial agents, by the disc diffusion method of Kirby- Bauer as described by Clinical Laboratory Standards Institute (CLSI) [25]. The antimicrobial agents used were: amikacin $(30 \mu \mathrm{g})$, gentamicin $(10 \mu \mathrm{g})$, ofloxacin $(5 \mu \mathrm{g})$, norfloxacin $(10 \mu \mathrm{g})$, nitrofurantoin $(300 \mu \mathrm{g})$, amoxicillin $(10 \mu \mathrm{g})$, nalidixic acid $(30 \mu \mathrm{g})$, co-trimoxazole $(1.25 /$ $23.75 \mu \mathrm{g})$ and ceftriaxone $(30 \mu \mathrm{g})$.

\section{Screening of ESBL producing strains of E.coli and K.pneumoniae}

Strains showing zone of inhibition of $\leq 25 \mathrm{~mm}$ for ceftriaxone were selected for confirmation test of ESBL, according to guidelines of CLSI [25].

\section{Phenotypic Confirmatory Disc Diffusion Test (PCDDT) for ESBL}

The potential ESBL producing strains of E.coli and K.pneumoniae were confirmed for ESBL production by phenotypic test. Briefly, a lawn culture of the isolated bacteria on Mueller Hinton agar (MHA) was made and ceftazidime $(30 \mu \mathrm{g})$ and the combination disc ceftazidime + clavulanic acid $(30 \mu \mathrm{g}+10 \mu \mathrm{g})$ was placed with $25 \mathrm{~mm}$ apart. An increase of $\geq 5 \mathrm{~mm}$ in zone of inhibition for 
ceftazidime + clavulanic acid compared to ceftazidime alone was confirmed as ESBL producing strains, as per recommendations of CLSI [25]. ESBL positive strains of E.coli and $K$. pneumoniae were selected to determine their susceptibility patterns against the second line of antimicrobial agent (imipenem $-10 \mu \mathrm{g}$ ), by the disc diffusion method of Kirby- Bauer as described by the CLSI [25]. The antimicrobial agents disc were obtained from Hi-Media Laboratories Pvt. Ltd., Mumbai, India. E.coli ATCC 25922 (ESBL negative) and K.pneumoniae ATCC 700603 (ESBL positive) were used as controls throughout the study.

All data were analyzed using SPSS statistical software (SPSS Inc., Chicago, IL).

\section{Results}

Out of a total of 6308 mid-stream urine specimens screened for significant bacteriuria, a total of $444(7.03 \%)$ and 145 (2.29\%) isolates of E.coli and K.pneumoniae were confirmed, respectively. Initial screening of these isolates for ESBL production showed 155/444 of E.coli and 70/ 145 of K.pneumoniae strains to be ceftriaxone resistant. Confirmation test (PCDDT) revealed 60/444 (13.51\%) of E.coli and 24/145 (16.55\%) of K.pneumoniae isolates to be ESBL positive (Table 1). A high rate of non-ESBL mediated ceftriaxone resistance was observed i.e. (95/155 = $63.33 \%)$ for E.coli and $(46 / 70=65.71 \%)$ for K.pneumoniae isolates.

The age varied from 7 months to 72 years and the sex ratio male:female was (1:2), of the patients from whom E.coli was isolated. The age range was 17 years to 70 years and the sex ratio male:female was (1:2.4) of the patients from whom K.pneumoniae was isolated. Clearly, the female group constituted the majority of the patients (Table 2).

A wide spectrum of resistance patterns to various antimicrobial agents was shown by the ESBL positive E.coli and K.pneumoniae strains. These E.coli strains showed a high degree of resistance (> 80\%-95\%) to ofloxacin, norfloxacin, co-trimoxazole, nalidixic acid and amoxicillin. The E.coli strains were much less resistant to gentamicin (23.33\%), nitrofurantoin (11.66\%) and least resistant to amikacin (6.66\%).

K.pneumoniae isolates were maximally resistant (100\%) to amoxicillin. A moderately high resistance of $66.66 \%$, $58.33 \%$ and $45.83 \%$ were shown to nalidixic acid, co-trimoxazole and gentamicin, respectively by these
Table 2 Age groups and sex-wise details of patients with ESBL positive E.coli and ESBL positive K.pneumoniae isolates

\begin{tabular}{cccccccc}
\hline $\begin{array}{c}\text { Age group } \\
\text { (years) }\end{array}$ & \multicolumn{2}{c}{ ESBL positive E.coli } & & \multicolumn{3}{c}{ ESBL positive K.pneumoniae } \\
\cline { 2 - 3 } \cline { 6 - 7 } & $\mathbf{M}$ & $\mathbf{F}$ & Total & & $\mathbf{M}$ & $\mathbf{F}$ & Total \\
\hline$<15$ & 6 & 2 & 8 & & 0 & 0 & 0 \\
$16-30$ & 2 & 20 & 22 & & 2 & 10 & 12 \\
$31-45$ & 8 & 10 & 18 & & 1 & 1 & 2 \\
$46-60$ & 2 & 2 & 4 & & 2 & 2 & 4 \\
$>60$ & 6 & 2 & 8 & & 4 & 2 & 6 \\
Total & 24 & 36 & 60 & & 9 & 15 & 24 \\
\hline
\end{tabular}

K. pneumoniae strains. Moderate resistance of $37.5 \%$ and $29.16 \%$ were shown toward the fluoroquinolone drugs norfloxacin and ofloxacin. Nitrofurantoin (20.83\% resistantance) and amikacin (12.5\% resistance) were the most effective antimicrobial agents against ESBL producing K.pneumoniae isolates. All the E.coli and K.pneumoniae isolates were susceptible (100\%) to the carbapenem, imipenem (Table 3).

A high multi-drug resistance (defined as resistant to $\geq 3$ different classes of antimicrobial agents) of $91.66 \%$ and 87.5\% respectively was observed among the ESBL producing strains of E.coli and K.pneumoniae. None of the strains of ESBL positive E.coli and K.pneumoniae were found to be sensitive to all the antimicrobial agents tested (Table 4).

\section{Discussion}

There is a paucity of documented literature on investigation of ESBLs producing uropathogens from Nepal [23]. To the best of our knowledge this is the first report from Nepal with an exclusive focus on investigating the current prevalence and antimicrobial susceptibility patterns among ESBL producing E. coli and $K$. pneumoniae - the predominant uropathogens, globally. The urine culture positivity rate was $9.32 \%$ (E.coli $=7.03 \%$ and K.pneumoniae $=2.29 \%$ ), which was low compared to that reported from South Africa (51\%) [26]. Nicaragua (30\%) [27] and India (39\%) [28]. ESBL production was more prevalent in K.pneumoniae strains, as compared to that in E.coli strains, which agrees with findings reported in previous studies [13,29]. The occurrence of ESBLs among clinical isolates vary greatly worldwide and geographically and are rapidly

Table 1 ESBL pattern of E.coli and Klebsiella pneumoniae isolated from urine specimens

\begin{tabular}{llll}
\hline $\begin{array}{l}\text { Bacterial } \\
\text { sp. isolated }\end{array}$ & $\begin{array}{l}\text { No. of isolates obtained / } \\
\text { total bacterial specimens } \\
\text { screened (\%) }\end{array}$ & $\begin{array}{l}\text { No. of screened and selected } \\
\text { isolates for ESBL confirmatory } \\
\text { test (ceftriaxone resistant) }\end{array}$ & $\begin{array}{l}\text { No. of isolates confirmed } \\
\text { by PCDDT / No. of isolates } \\
\text { obtained (\%) }\end{array}$ \\
\hline E.coli & $444 / 6308(7.03)$ & 155 & $60 / 444(13.51)$ \\
K.pneumoniae & $145 / 6308(2.29)$ & 70 & $24 / 145(16.55)$ \\
\hline
\end{tabular}


Table 3 Antimicrobial resistance patterns of confirmed ESBL producing E.coli and K.pneumoniae isolates from urine specimens

\begin{tabular}{lll}
\hline Antibiotic & $\begin{array}{l}\text { ESBL positive } \\
\text { E.coli }(\mathbf{n}=60)\end{array}$ & $\begin{array}{l}\text { ESBL positive } \\
\text { K.pneumoniae }(\mathbf{n}=\mathbf{2 4})\end{array}$ \\
& T/ R (\%) & T/R (\%) \\
\hline Amikacin & $60 / 04(6.66)$ & $24 / 3(12.5)$ \\
Gentamicin & $60 / 14(23.33)$ & $24 / 11(45.83)$ \\
Ofloxacin & $60 / 49(81.66)$ & $24 / 07(29.16)$ \\
Norfloxacin & $60 / 54(90.0)$ & $24 / 9(37.5)$ \\
Nitrofurantoin & $60 / 07(11.66)$ & $24 / 05(20.83)$ \\
Amoxycillin & $60 / 57(95.0)$ & $24 / 24(100.0)$ \\
Nalidixic acid & $60 / 57(95.0)$ & $24 / 16(66.66)$ \\
Co-trimoxazole & $60 / 51(85.0)$ & $24 / 14(58.33)$ \\
Ceftriaxone & $60 / 60(100.0)$ & $24 / 24(100.0)$ \\
Ceftazidime & $60 / 60(100.0)$ & $24 / 24(100.0)$ \\
Imipenem & $60 / 0(0.0)$ & $24 / 0(0.0)$ \\
\hline
\end{tabular}

$\mathrm{T}=$ Total no. of isolates tested; $\mathrm{R}=$ No. of isolates resistant.

changing overtime. ESBL prevalence was 29.86\% (E.coli= $13.51 \%$ and K.pneumoniae $=16.55 \%$ ). It was low as compared to a study done in India [30], which reported nearly $40 \%$ of urinary isolates of E.coli and K.pneumoniae were ESBL positive. The highest isolation rate of ESBLs producing K.pneumoniae had been reported from the Latin America (54.4\%), the western Pacific (24.6\%) and Europe (22.6\%). The frequency of ESBL producing E.coli in these areas was reported to be $8.5 \%, 7.8 \%$ and $5.3 \%$, respectively [31]. Females showed a higher rate of isolation of ESBL producing E.coli (60\%) and K.pneumoniae (62.5\%), which parallels the findings as reported earlier [32,33]. This study revealed a higher occurrence of ESBL producing uropathogens in the adult age group of 16-45 years, which is similar to that reported in a study done in Pakistan [1].

The high rates for non - ESBL mediated ceftriaxone resistant E.coli (63.33\%) and K.pneumoniae (65.71\%) isolates may be due to their different mechanisms for resistance such as the production of ampC $\beta$ lactamase, metallo-betalactamase, etc. [34]. This further limits the therapeutic options available to treat these infections.

Table 4 Antimicrobial resistance patterns among ESBL positive E.coli and ESBL positive K.pneumoniae urine isolates

\begin{tabular}{|c|c|c|}
\hline $\begin{array}{l}\text { ESBL positive } \\
\text { E.coli isolates } \\
\text { no. }(\%)\end{array}$ & $\begin{array}{l}\text { ESBL positive } \\
\text { K.pneumoniae } \\
\text { isolates no. (\%) }\end{array}$ & $\begin{array}{l}\text { Resistance to no. of } \\
\text { classes of antibiotics } \\
\text { tested }\end{array}$ \\
\hline 0 & 0 & 0 \\
\hline 0 & 0 & 1 \\
\hline 5 (8.34) & $3(12.5)$ & 2 \\
\hline 55(91.66) & $21(87.5)$ & $\geq 3$ \\
\hline
\end{tabular}

The susceptibility patterns of the ESBL producing E.coli and K. pneumoniae varied widely with the class of antimicrobial agents used. All isolates were uniformly resistant (100\%) to the third generation cephalosporin, ceftriaxone. All ESBL positive K.pneumoniae strains were resistant (100\%) to amoxicillin, while resistance rate for ESBL positive E.coli was 95\%. In a study reported from Madagascar [35], 80\% of the E.coli isolates were resistant to amoxicillin. In our study E.coli showed a high resistance rate $(85 \%)$ to co-trimoxazole where as the K.pneumoniae showed resistance rate $(58.33 \%)$ to co-trimoxazole. A comparable resistance rate of $80 \%$ and $45 \%$ to co-trimoxazole was shown among ESBL producing E.coli and K.pneumoniae isolates in a study conducted in Iran [36]. A striking feature in this study was that the quinolones, ofloxacin, norfloxacin and nalidixic acid demonstrated a high resistance varying from $>80 \%$ to $95 \%$ among ESBL positive E.coli, while $29.16 \%$ to $66.66 \%$ of $K$. pneumoniae were resistant. This parallels with the findings of the studies done in Indore, India [37] and Bangladesh [38]. A lower resistance rates varying from $24 \%$ to $44 \%$ to norfloxacin had been reported in European countries [39]. This probably reflects a better management of these clinically significant infections in resource-rich countries.

Conversely, this study revealed resistance rates of $45.83 \%$ and $12.5 \%$ to the aminoglycosides, gentamicin and amikacin by ESBL positive K.pneumoniae strains. In comparison, E.coli shown a much low resistance rate gentamicin (23.33\%) and amikacin (6.66\%). In contrast. K. pneumoniae showed resistance to gentamicin (69\%) and amikacin (38\%) while 59\% and 33\% resistance rates were shown by E.coli isolates in a study done in Indore, India [37]. A resistance rate of $46.7 \%$ to gentamicin was shown by K.pneumoniae isolates in a report from Karachi, Pakistan [40], which is similar to results in this study. This report supports that aminoglycosides have good activity against clinically important gram negative bacilli [41]. The resistance rates of ESBL positive E.coli and K.pneumoniae to nitrofurantoin were $11.66 \%$ and $20.83 \%$, respectively. Parallel resistance rate $(12 \%)$ by E.coli isolates was shown in a report from Indore, India [37].

A significant finding in this report was that aminoglycosides and nitrofurantoin proved to be the optimal drugs. This may be due to the restricted use of these drugs in our hospital setting and nitrofurantoin is usually reserved to be prescribed only in cases of UTIs since it is excreted and concentrated in urine. All ESBL positive E.coli and K.pneumoniae strains in this study were sensitive (100\%) to imipenem. A very high MDR rates of $91.66 \%$ and $87.5 \%$ among ESBL positive E.coli and K.pneumoniae were obtained in this study. A comparable MDR rate of $83 \%$ among E.coli isolates was reported in a study done in Peshawar, Pakistan [1]. 
Nepal represents a unique geographical terrain with sparsely-populated areas mainly in hilly and mountainous regions, severely limited health-care resources and a low-income economy. And the health care facilities are concentrated in the capital city of Kathmandu and people come here for treatment, from far-flung areas of the country.These people may acquire pathogens and when they return to their native areas in villages, may act as carriers of drug resistant pathogens.

Multi-center studies involving major health-care facilities in other parts of the country are required to have a more clear picture of ESBL producing uropathogens. Further, molecular epidemiological studies of resistance genes among the uropathogens would provide us much needed details on bacterial clones circulating in this region.

\section{Conclusion}

This report documents the emergence and occurrence of ESBL producing E.coli and K.pneumoniae in urinary isolates in Nepal. A moderately high prevalence of ESBL producing E.coli and K.pneumoniae was observed and confirmed in the urinary isolates. A strict hospital infection control policies and a prudent anti-microbials use regimens are to be adopted by the physicians. It is essential and mandatory to have a regular and routine monitoring of ESBL producing clinical isolates in clinical laboratories.

\section{Abbreviations \\ MSU: Mid stream urine; ESBL: Extended spectrum beta-lactamase; NCCLS: National committee on clinical laboratory standards; PCDDT: Phenotypic confirmatory disk diffusion test; CLSI: Clinical laboratory standards institute; UTIs: Urinary tract infections; MHA: Mueller Hinton Agar; MDR: Multi drug resistance.}

\section{Competing interests}

The authors declare that they have no competing interests.

\section{Authors' contributions}

AC did the interpretation, statistical analysis of data and drafted the manuscript. CDS has been involved in conception, design and acquisition of data. Both authors have read and approved the final manuscript.

\section{Acknowledgement}

The authors thank the management of Kathmandu Medical College Teaching Hospital for providing the necessary facilities to conduct this study. Our thanks also goes to the technical staff of the Microbiology Laboratory, $\mathrm{KMCTH}$ for their help in carrying out the laboratory tests.

Received: 23 July 2013 Accepted: 23 November 2013

Published: 25 November 2013

\section{References}

1. Ullah F, Malik SA, Ahmed J: Antibiotic susceptibility pattern and ESBL prevalence in nosocomial Escherichia coli from urinary tract infections in Pakistan. Afr J Biotechnol 2009, 8(16):3921-3926.

2. Cox CE: Nosocomial urinary tract infections. Urol 1988, 32(3):210-215.

3. Gonzalez CM, Schaeffer AJ: Treatment of urinary tract infection: what's old, what's new, and what works. World J Urol 1999, 17(6):372-382.

4. Coque TM, Baquero F, Canton R: Increasing prevalence of ESBL producing enterobacteriaceae in Europe. Eurosurveillance 2008, 13(47):1-11.
5. Paterson DL, Bonomo RA: Extended spectrum $\beta$-lactamases: a clinical update. Clin Microbiol Rev 2005, 18(4):657-686.

6. Bradford PA: Extended spectrum $\beta$-lactamases in the 21st century: characterization, epidemiology, and detection of this important resistance threat. Clin Microbiol Rev 2001, 14(4):933-951.

7. Jacoby GA, Munoz-Price LS: The new beta-lactamases. New Engl J Med 2005, 352(4):380-391.

8. Rupp ME, Fey PD: Extended spectrum $\beta$-lactamase (ESBL)- producing enterobacteriaceae: considerations for diagnosis, prevention and drug treatment. Drugs 2003, 63(4):353-365.

9. Meyer KS, Urban C, Eagan JA, Berger BJ, Rahal JJ: Nosocomial outbeak of Klebsiella infection resistant to late-generation cephalosporins. Ann Intern Med 1993, 119:353-358.

10. Naumovsky L, Quinn JP, Miyashiro D, Patel M, Bush K, Singer SB, et al: Outbreak of ceftazidime resistance due to a novel extended spectrum $\beta$-lactamase in isolates from cancer patients. Antimicrob Agents Chemother 1992, 36:1991-1996.

11. Schiappa DA, Hayden MK, Matushek MG, Hashemi FN, Sullivan J, Smith KY et al: Ceftazidime resistant Klebsiella pneumoniae and Escherichia coli blood stream infection: a case control and molecular epidemiologic investigation. J Infect Dis 1996, 174:529-536.

12. Paterson DL, Mulazimoglu L, Casellas JM, Ko W-C, Goossens H, Gottberg AV, et al: Epidemiology of ciprofloxacin resistance and its relationship to extended spectrum $\beta$-lactamase production in Klebsiella pneumoniae isolates causing bacteremia. Clin Infect Dis 2000, 30:473-478.

13. Spanu T, Luzzaro F, Perilli M, Amicosante G, Toniolo A, Fadda G: The Italian ESBL Study Group. Occurrence of extended spectrum $\beta$-lactamases in members of the family Enterobacteriaceae in Italy: implications for resistance to $\beta$-lactams and other antimicrobial drugs. Antimicrob Agents Chemother 2002, 46:196-202.

14. Jacoby GA, Sutton L: Properties of plasmids responsible for production of extended spectrum $\beta$-lactamases. Antimicrob Agents Chemother 1991, 35:164-169

15. Poirel M, Le Thomas I, Naas T, Karim A, Nordmann P: Biochemical sequence analyses of GES-1, a novel class A extended spectrum $\beta$-lactamase, and the Class I integrin In52 from Klebsiella pneumoniae. Antimicrob Agents Chemother 2000, 44:622-632.

16. Bonnet R: Growing group of extended spectrum $\beta$-lactamases: the CTX-M enzymes. Antimicrob Agents Chemother 2004, 48(1):1-14.

17. Falagas ME, Karageorgopoulos: Extended spectrum $\beta$-lactamase-producing organisms. J Hosp Infect 2009, 73(4):345-354.

18. Reinert RR, Low DE, Rossi F, Zhang X, Wattal C, Dowzicky MJ: Antimicrobial susceptibility among organisms from the Asia/ Pacific Rim, Europe and Latin and North America collected as part of TEST and the in vitro activity of tigecycline. J Antimicrob Chemother 2007, 60(5):1018-1029.

19. Villegas MV, Kattan JN, Quinteros MG, Casselas JM: Prevalence of extended-spectrum $\beta$-lactamases in South America. Clin Microbiol Infect 2008, 14(Suppl. 1):154-158.

20. Sader HS, Jones RN, Gales AC, Silva JB, Pignatari AC: SENTRY antimicrobial surveillance program report; Latin America and Brazilian results for 1997 through 2001. Braz I Infect Dis 2004, 8(1):25-79.

21. Poudyal S, Bhatta DR, Shakya G, Upadhyaya B, Dumre SP, Buda G, et al: Extended spectrum $\beta$-lactamase producing multidrug resistant clinical bacterial isolates at National Public Health Laboratory, Nepal. Nepal Med Coll J 2011, 13(1):34-38.

22. Shrestha S, Amatya R, Dutta R: Prevalence of extended spectrum beta lactamase (ESBL) production in gram negative isolates from pyogenic infection in tertiary care hospital of Eastern Nepal. Nepal Med Coll J 2011, 13(3):186-189.

23. Baral P, Neupane S, Marasini BP, Ghimire KR, Lekhak B, Shrestha B: High prevalence of multidrug resistance in bacterial uropathogens from Kathmandu, Nepal. BMC Res Notes 2012, 5:38.

24. Collee JG, Miles RS, Watt B: Tests for identification of bacteria. In Mackie and McCartney Practical Medical Microbiology. 14th edition. Edited by Collee JG, Fraser AG, Marmion BP, Simmons A. New York: Churchill Livingstone; 1996:131-149.

25. Clinical Laboratory Standards Institute: Performance standards for antimicrobial susceptibility testing; Twenty First informational supplement (M 100-S21). Wayne PA: Clinical and Laboratory Standards Institute; 2011.

26. Habte TM, Dube S, Ismail N, Hoosen AA: Hospital and community isolates of uropathogens at a tertiary hospital in South Africa. S Afr Med J 2009, 99:584-587. 
27. Matute AJ, Hak E, Schurink CAM, MCArthur A, Alonso E, Pantagua M, et al: Resistance of uropathogens in symptomatic urinary tract infections in Leon, Nicaragua. Int J Antimicrob Agents 2004, 23:506-509.

28. Tambekar DH, Dhanorkar DV, Gulhane DR, Khanadelwal VK, Dudhane MN: Antibacterial susceptibility of some urinary tract pathogens to commonly used antibiotics. Afr J Biotechnol 2006, 5:1562-1565.

29. Durmaz R, Durmaz B, Koroglu M, Tekerekoglu MS: Detection and typing of extended-spectrum $\beta$-lactamases in clinical isolates of the family Enterobacteriaceae in a medical center in Turkey. Microb Drug Resist 2001, 7:171-175.

30. Babypadmini S, Appalaraju B: Extended spectrum lactamase in urinary isolates of E.coli and Klebsiella pneumoniae - prevalence and susceptibility patterns in a tertiary care hospital. Indian J Med Microbiol 2004, 22:172-174

31. Aminzadeh Z, Sadat KM, Sha'bani M: Bacteriuria by extended spectrum beta-lactamase producing E.coli and Klebsiella pneumoniae isolates in a government hospital in south of Tehran, Iran. Iran J Kidney Dis 2008, 2:197-200.

32. Ahmed SM, Jakribettu RP, Koyakutty S, Arya B, Shakir VPA: Urinary tract infections - an overview on the prevalence and the anti-biogram of gram negative uropathogens in a tertiary care center in North Kerala, India. J Clin Diagn Res 2012, 6:1192-1195.

33. Oladeinde BH, Omoregie R, Olley M, Anunibe JE: Urinary tract infections in a rural community of Nigeria. North Amer J Med Sci 2011, 3:75-77.

34. Dalela G, Gupta S, Jain DK, Mehta P: Antibiotic resistance patterns in uropathogens at a tertiary care hospital at Jhalawar with special reference to ESBL, AmpC b-lactamase and MRSA production. J Clin Diagn Res 2012, 6(4):645-651.

35. Randrianirina F, Soares J-L, Carod J-F, Ratsima E, Thonnier V, Combe P, et al: Antimicrobial resistance among uropathogens that cause community-acquired urinary tract infections in Antananarivo, Madagascar. J Antimicrob Chemother 2007, 59:309-312.

36. Behrooozi A, Rahbar M, Yousefi JV: Frequency of extended spectrum beta-lactamase (ESBLs) producing Escherichia coli and Klebsiella pneumoniae isolated from urine in an Iranian 1000-bed tertiary care hospital. Afr J Microbiol Res 2010, 4(9):881-884

37. Pathak A, Marothi Y, Kekre V, Mahadik K, Macaden R, Lundborg CS: High prevalence of extended spectrum $\beta$-lactamase producing pathogens: results of a surveillance study in two hospitals in Ujjain, India. Infect Drug Resist 2012, 5:65-73.

38. Alipourfard I, Nili NY: Antibiogram of extended spectrum beta-lactamase (ESBLs) producing Escherichia coli and Klebsiella pneumoniae isolated from hospital samples. Bangladesh J Med Microbiol 2010, 4(1):32-36.

39. van der Donk CFM, van de Bovenkamp JHB, De Brauwer EIGB, De Mol P, Feldhoff K-H, Kalka-Moll WM, et al: Antimicrobial resistance and spread of multi drug resistant Escherichia coli isolates collected from nine urology services in the Euregion Meuse-Rhine. PLoS One 2012, 7(10):e47707.

40. Abdullah FE, Mushtaq A, Irshad M, Rauf H, Afzal N, Rasheed A: Current efficacy of antibiotics against Klebsiella isolates from urine samples - a multi-centric experience in Karachi. Pak J Pharm Sci 2013, 26(1):11-15.

41. Gonzalez LS, Spencer JP: Aminoglycosides: a practical review. Am Fam Physician 1998, 58(8):1811-1820.

\section{doi:10.1186/1756-0500-6-487}

Cite this article as: Chander and Shrestha: Prevalence of extended spectrum beta lactamase producing Escherichia coli and Klebsiella pneumoniae urinary isolates in a tertiary care hospital in Kathmandu, Nepal. BMC Research Notes 2013 6:487.

\section{Submit your next manuscript to BioMed Central and take full advantage of:}

- Convenient online submission

- Thorough peer review

- No space constraints or color figure charges

- Immediate publication on acceptance

- Inclusion in PubMed, CAS, Scopus and Google Scholar

- Research which is freely available for redistribution 